\title{
Intestinal Folate Absorption
}

\section{5-METHYLTETRAHYDROFOLIC ACID}

\author{
Williamson Strum, Peter F. Nixon, Joseph B. Bertino, and \\ HENRY J. BINDER \\ From the Departments of Internal Medicine and Pharmacology, Yale \\ University, New Haven, Connecticut 06510
}

A в S T R A C T Intestinal absorption of the monoglutamate form of the principal dietary and circulating folate compound, 5-methyltetrahydrofolic acid (5-MTHF), was studied in the rat utilizing a synthetic highly purified radiolabeled diastereoisomer. Chromatography confirmed that the compound was not altered after transfer from the mucosa to the serosa. Accumulation against a concentration gradient was not observed in duodenal, jejunal, or ileal segments at 5-MTHF concentration from 0.5 to 500 nmoles/liter. Unidirectional transmural flux determination also did not indicate a significant net flux. Mucosal to serosal transfer of 5-MTHF was similar in all segments of the intestine and increased in a linear fashion with increased initial mucosal concentrations. Further, no alteration in 5-MTHF transfer was found when studied in the presence of metabolic inhibitors or folate compounds.

These results indicate that $5-\mathrm{MTHF}$ is not absorbed by the rat small intestine by a carrier-mediated system and suggest that 5-MTHF transfer most likely represents diffusion.

\section{INTRODUCTION}

The mechanism of folate ${ }^{1}$ absorption in man and experimental animal is not established. Both the paucity of

This work was presented in part at a joint meeting of the American Society of Clinical Investigation and American Federation of Clinical Research, 3 May 1970 and appeared in abstract form (1970. Clin. Res. 18: 389.).

Dr. Bertino is a recipient of a Career Development Award of the National Cancer Institute. Dr. Nixon was the recipient of a Merck, Sharp \& Dohme International Fellowship in Clinical Pharmacology, and his present address is Department of Biochemistry, John Curtin School of Medical Research, Australian National University, Canberra City, Australia. Dr. Strum was a trainee of the National Cancer Institute (CA 05138), and his present address is Seymour Johnson A.F.B., N. C.

Received for publication 4 March 1971.

${ }^{1}$ Abbreviations used in this paper: DHF, dihydrofolic acid; FA, folic acid (pteroylmonoglutamate); FA poly- experimental data and conflicting results have prevented an adequate understanding of the problem. Most previous studies have been devoted to the absorption of either folic acid (FA) or FA polyglutamates (1-10). However, the predominant circulating and storage forms of folate are neither FA nor FA polyglutamates but rather reduced forms of folate, principally 5-methyltetrahydrofolic acid (5-MTHF) (11). Moreover, the principal dietary folate compound is probably also 5-MTHF or polyglutamate forms of 5-MTHF (12). Therefore, understanding of folate absorption requires investigation of the absorption of 5-MTHF and 5-MTHF polyglutamates.

In this communication we report our studies of the absorption of 5-MTHF. The synthesis of the physiologically active diastereoisomer of radiolabeled 5-MTHF in our laboratory has facilitated these studies in the rat.

\section{METHODS}

Materials. $\mathrm{FA},{ }^{2}$ labeled by tritium at the $3^{\prime}-, 5^{\prime}-$, and $9^{\prime}-$ positions with a specific activity of $250 \mu \mathrm{Ci} / \mu$ mole, L-alanine${ }^{14} \mathrm{C}^{3}$ and formaldehyde $-{ }^{14} \mathrm{C}^{3}$ were obtained commercially. The tritium-labeled physiologically active diastereoisomer of 5-MTHF was prepared as previously published (13). Briefly, tritium-labeled FA was reduced chemically to dihydrofolic acid (DHF) using the method of Blakley (14). The DHF was then enzymatically reduced to tetrahydrofolic acid (THF) by a highly purified dihydrofolate reductase (15). The N-5,10-methylene derivative was prepared from THF by the addition of formaldehyde, and reduced to 5-MTHF by sodium borohydride. $5-\mathrm{MTHF}-{ }^{14} \mathrm{C}$ was prepared in the same manner except unlabeled FA was used as the starting material, and formaldehyde $-{ }^{14} \mathrm{C}$ was added to introduce the label on the methyl group. The radiolabeled compounds were purified by column chromatography, first on A-25 DEAE-Sephadex then on Sephadex G-25. The purified ma-

glutamates, folic acid polyglutamates (usually 3- to 7-glutamates) ; 5-fTHF, 5-formyltetrahydrofolic acid; 10-fTHF, 10-formyltetrahydrofolic acid; 5-MTHF, 5-methyltetrahydrofolic acid; MTX, methotrexate; pABG, $p$-aminobenzoylglutamate; THF, tetrahydrofolic acid. Folate is used to refer to all folate compounds, both reduced and nonreduced.

${ }^{2}$ Amersham/Searle Corp., Des Plaines, Ill.

${ }^{3}$ New England Nuclear Corp., Boston, Mass. 
terials had specific activities of either $250 \mu \mathrm{Ci} / \mu$ mole for ${ }^{3} \mathrm{H}$ or $50 \mu \mathrm{Ci} / \mu$ mole for ${ }^{14} \mathrm{C}$ and were greater than 99 and $95 \%$ radiochemically pure, respectively. The compounds were stored at $-20^{\circ} \mathrm{C}$ as a solution with sodium ascorbate (3 $\mathrm{mg} / \mathrm{ml}$ ) at $\mathrm{pH} 6.0$.

Identification of folate compounds by chromatography. Samples were desalted by chromatography (16) through a Sephadex G-15 column equilibrated with $0.1 \mathrm{M}$ mercaptoethanol and eluted by the same solvent. Fractions, which contained radioactivity or folate markers, were pooled and applied to a $0.9 \times 27 \mathrm{~cm}$ column of A-25 DEAE-Sephadex equilibrated with $0.1 \mathrm{M}$ phosphate buffer, $\mathrm{pH} 6.0$, containing $20 \mathrm{~mm}$ mercaptoethanol. Materials were eluted by phosphate buffer, $\mathrm{pH} 6.0$, the concentration of which was increased linearly from 0.1 to 2.0 moles/liter, also containing $20 \mathrm{~mm}$ mercaptoethanol. The final concentration of $2.0 \mathrm{M}$ phosphate buffer was obtained after passage of $500 \mathrm{ml}$ of eluting buffer. Nonradioactive markers of 5-MTHF, FA, 5-formyltetrahydrofolic acid (5-fTHF), and $p$-aminobenzoylglutamate ( $\mathrm{pABG}$ ) were added with the sample when applicable. Fractions of $2.5 \mathrm{ml}$ were collected and monitored by radioactivity and by ultraviolet absorbance spectra.

Intestinal absorption studies in vitro. Absorption was studied by several methods: everted sacs (17), mucosal scrapings (18), and unidirectional transmural fluxes (19) in male, albino Sprague-Dawley rats weighing 250-350 g.

Everted gut sacs were prepared according to the method of Wilson and Wiseman (17), modified as previously described (20). The buffer system utilized consisted of $122 \mathrm{~mm}$ sodium chloride, $4.9 \mathrm{~mm} \mathrm{KCl}, 26.5 \mathrm{~mm}$ sodium bicarbonate, and $1.2 \mathrm{~mm}$ potassium phosphate, $\mathrm{pH} 7.4$. Each sac was approximately $10 \mathrm{~cm}$ long, and its wet weight was approximately $500 \mathrm{mg}$. The most proximal small intestinal segment was duodenum. The jejunal sacs were the next three segments; the ileal sacs were the three most distal segments. $1 \mathrm{ml}$ of the buffer was placed inside the sac, which was then placed in a flask containing $5 \mathrm{ml}$ of buffer solution and varying concentrations of 5-MTHF and approximately $1.5 \mu \mathrm{Ci} 5-\mathrm{MTHF}_{-}{ }^{3} \mathrm{H}$. In certain experiments the serosal fluid contained buffer only, and in other studies the serosal media had the same concentration of 5-MTHF as the mucosal solution. The flasks were gassed with $\mathrm{O}_{2}-\mathrm{CO}_{2}(95: 5$, $\mathrm{v} / \mathrm{v}$ ) and incubated at $37^{\circ} \mathrm{C}$ with continuous shaking for 50 min. In one series of experiments in which anaerobic incubation conditions were desired, nitrogen replaced the $\mathrm{O}_{2}-\mathrm{CO}_{2}$ gas mixture. At the end of the incubation period, each sac was removed, and the serosal fluid drained by gravity. The wet weight of each sac was determined. In those experiments in which 5-MTHF was not initially present in the serosal media, the serosal sample was diluted to $2.0 \mathrm{ml}$, and a portion was added to Bray's solution and counted in a Packard Tri-Carb three-channel liquid scintillation spectrometer with automatic external standardization. In these studies, 5-MTHF transfer, expressed in $\mathrm{pg} / 50 \mathrm{~min}$ per $0.5 \mathrm{~g}$ wt tissue weight, is defined as the amount of 5MTHF present in the serosal solution at the end of the incubation. In those experiments in which an equal concentration of 5-MTHF was present initially in both the mucosa and serosa solutions, portions of the final mucosal and serosal solutions were also counted. The mucosal to serosal ratio of 5-MTHF was then determined. The transport of $5 \mathrm{~mm}$ L-alanine was also determined in a series of experiments to demonstrate active transport in this preparation.

Mucosal scrapings were prepared for incubation as described by Schultz, Fuisz, and Curran (18) with 5-MTHF concentrations of 0.5 and 50 nmoles/liter. The results were expressed as the ratio of 5-MTHF in intracellular fluid compared with its concentration in the extracellular media.

Unidirectional transmural fluxes of 5-MTHF were determined under open-circuited conditions using the methods and apparatus described by Schultz and Zalusky (19). Flat sheets of rat jejunum were mounted between Lucite chambers. $5-\mathrm{MTHF}^{3} \mathrm{H}$ was added to one bathing solution, and after a $40 \mathrm{~min}$ equilibration period, its rate of appearance in the opposite solution was determined. Mucosa to serosa and serosa to mucosa fluxes $\left(J_{m \rightarrow s}\right.$, and $J_{s \rightarrow m}$, respectively) were determined at the same time on adjacent pieces of tissue from the same animal. Experiments to determine Lalanine unidirectional transmural fluxes were also performed (21). In all experiments both sides of the tissue was bathed with identical solutions maintained at $37^{\circ} \mathrm{C}$ and bubbled continuously with $\mathrm{O}_{2}-\mathrm{CO}_{2}(95: 5, \mathrm{v} / \mathrm{v})$. In this series of experiments the composition of the bathing solution in millmoles per liter was $\mathrm{NaCl}, 140 ; \mathrm{KHCO}_{3}, 10 ; \mathrm{K}_{2} \mathrm{HPO}_{4}$, $1.2 ; \mathrm{KH}_{2} \mathrm{PO}_{4}, 0.6 ; \mathrm{CaCl}_{2}, 1.2 ; \mathrm{MgCl}_{2}, 1.2$.

Statistics. Statistical significance was determined by the Student's $t$ test (22).

\section{RESULTS}

Identification of transported folate compounds. When everted jejunal sacs were incubated in mucosal media containing 5-MTHF ${ }^{3} \mathrm{H},{ }^{14} \mathrm{C}$ (500 nmoles/liter), the radiolabels were recovered unchanged from the serosal media after 60 min of incubation (Fig. 1), thus indicating no metabolic alteration of the original material occurred during the process of mucosal to serosal transfer.

Transport with no concentration gradient and mucosal scrapings. Everted sacs of duodenum, jejunum, and ileum were incubated with $50 \mathrm{~min}$ at $37^{\circ} \mathrm{C}$ with $5-\mathrm{MTHF}$ on each side at equal concentration at 500,50 , 5.0 , and 0.5 nmoles/liter, and at no time was the ratio of serosal to mucosal concentration greater than 1. An average of 12 experiments was performed at each concentration. Preliminary studies using identical methodology demonstrated that $5 \mathrm{~mm}$ L-alanine could be accumulated against a concentration gradient by jejunal mucosa. In studies using scrapings of jejunal mucosa incubated with 50 and $0.5 \mathrm{~nm} 5-\mathrm{MTHF}$, the ratio of intracellular to extracellular 5-MTHF concentration did not exceed unity.

Unidirectional transmural fluxes. At 5-MTHF concentrations of both 3000 and 3 nmoles/liter, there was no statistical difference between $\mathrm{J}_{\mathrm{ms}}$ and $\mathrm{J}_{\mathrm{sm}}$ (Table I), and the $\mathrm{J}_{\text {net }}$ present could be explained by a spontaneous transmural potential difference no more than $1.9 \mathrm{mv}$ (mucosa negative). ${ }^{*}$ Preliminary studies demonstrated a net L-alanine flux of $0.56 \pm 0.12 \mu$ moles $/ \mathrm{hr} \cdot \mathrm{cm}^{2}$.

${ }^{4}$ The unidirectional fluxes under open-circuited conditions were analyzed by the Ussing flux ratio equation (23):

$$
\frac{\mathrm{J}_{\mathrm{ms}}}{\mathrm{J}_{\mathrm{sm}}}=\frac{\mathrm{a}^{\mathrm{m}}}{\mathrm{a}^{\mathrm{s}}} e^{\mathrm{ZF} \Delta \psi / \mathrm{RT}},
$$

where $J_{m s}$ and $J_{s m}$ are the mucosal to serosal flux and serosal to mucosal flux, respectively; $\mathrm{a}^{\mathrm{m}}$ and $\mathrm{a}^{\mathrm{s}}$ are the 


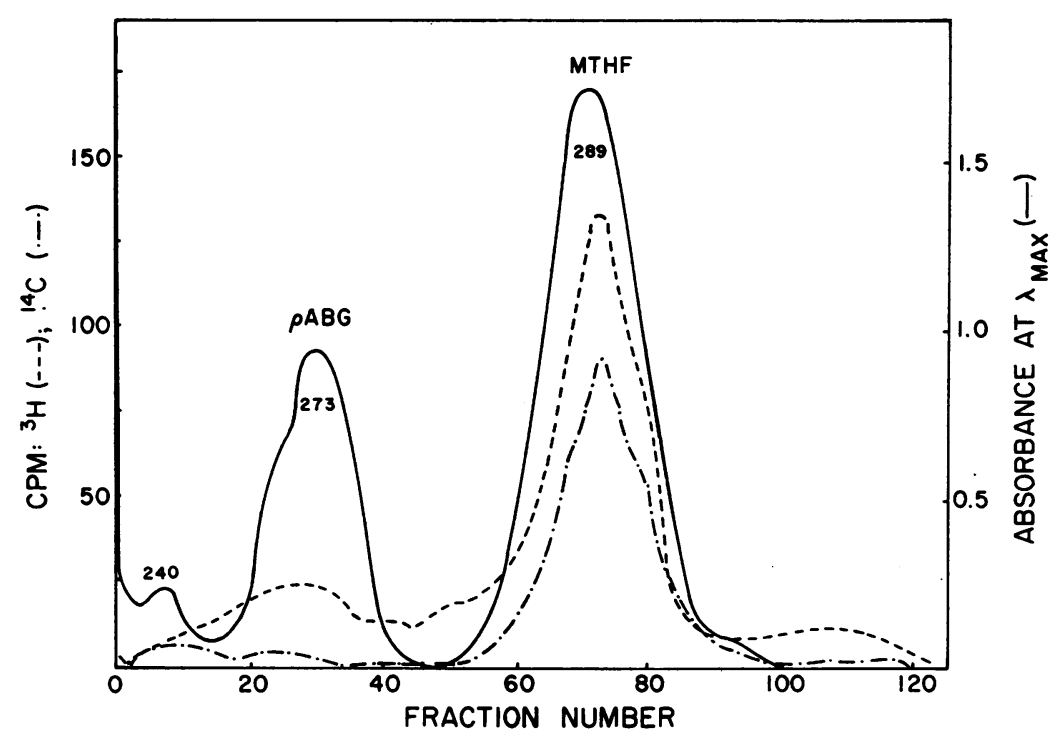

FIgURE 1 Chromatographic identification on DEAE-Sephadex (16) of folate compounds found in serosal media of everted jejunal sac incubated in mucosal media containing $5-\mathrm{MTHF}-{ }^{8} \mathrm{H},{ }^{14} \mathrm{C}$. Essentially all radioactivity was identified in the $289 \mathrm{~m} \mu$ peak which cochromatographs with unlabeled 5-MTHF. 5-MTHF and pABG were added to the column as markers (see Methods).

All of the following everted sac experiments were performed with 5-MTHF present initially only in the mucosal media.

Transfer of 5-MTHF vs. time. Everted jejunal sacs containing $50 \mathrm{nM} 5-\mathrm{MTHF}$ in the mucosal media were incubated for $5,15,30$, and $50 \mathrm{~min}$, and an increase transfer of 5-MTHF was noted with increasing incubation time (Fig. 2).

5-MTHF transfer: location and variation with concentration. Transfer of 5-MTHF from mucosa to serosa at $0.05-50.0 \mu \mathrm{moles} /$ liter was quantitatively simi-

TABLE I

Transmural Fluxes of 5-MTHF*

\begin{tabular}{cccc}
\hline $\begin{array}{c}\text { Concen- } \\
\text { tration }\end{array}$ & $\mathrm{J}_{\mathrm{ms}}$ & $\mathrm{J}_{\mathrm{sm}}$ & $\mathrm{J}_{\text {net }}$ \\
\hline nmoles/liter & & & \\
3000 & $2944 \pm 170(30)$ & $2559 \pm 268(21)$ & $385 \pm 317$ \\
3 & $4.89 \pm 0.32(40)$ & $4.55 \pm 0.18(29)$ & $0.34 \pm 0.37$
\end{tabular}

* Unidirectional transmural fluxes determined utilizing the method and apparatus of Schultz and Zalusky (19) as described in the text. 5-MTHF flux is expressed as $10^{-2}$ pmoles/ $\mathrm{hr} \cdot \mathrm{cm}^{2}$. The number of flux determinations is in parenthesis.

chemical activity of the ion in the mucosal and serosal media, respectively; $z, F, R$, and $T$ are, respectively, the change of the ion, the Faraday, the gas constant, and absolute temperature; and $\Delta \psi$ is the electrical potential difference across the jejunum. lar in everted sacs of duodenum, jejunum, and ileum (Fig. 3). The increase in transfer at $0.05 \mu \mathrm{mole} /$ liter in jejunal segments as compared with duodenal and ileal segments was not statistically significant. The effect of a 1000 -fold increment in substrate concentration (0.05$50 \mu$ moles/liter) on transfer of 5-MTHF from mucosa to serosa of the duodenum, jejunum, and ileum was to produce a linear increase in the total amount transferred (Fig. 3).

Effect of modified incubation conditions on 5-MTHF transfer. Everted jejunal sacs were incubated in a mucosal media containing $50 \mathrm{~nm}$ 5-MTHF under anaerobic conditions, in a sodium-free medium, and in the presence of $10^{-4} \mathrm{M}$ dinitrophenol. No significant decrease in mucosal to serosal transfer was observed as compared with paired controls. $500 \mathrm{~nm}$ 5-MTHF transfer in the presence of $10 \mathrm{~mm}$ glucose was similar to controls (Fig. 4).

Effect of folate analogues on 5-MTHF transfer. Everted jejunal sacs were incubated in a mucosal media containing $50 \mathrm{~nm}$ 5-MTHF and with $500 \mathrm{~nm}$ FA, 500 nM 5-fTHF, or $500 \mathrm{~nm}$ methotrexate (MTX). No significant decrease in mucosal to serosal transfer was noted in those tissues incubated with FA and MTX. A significant increase in transfer of 5-MTHF was noted during incubation with 5-fTHF $(P<0.05)$ (Fig. 5).

\section{DISCUSSION}

Previous investigations of folate absorption utilizing FA have yielded conflicting results: evidence of active 


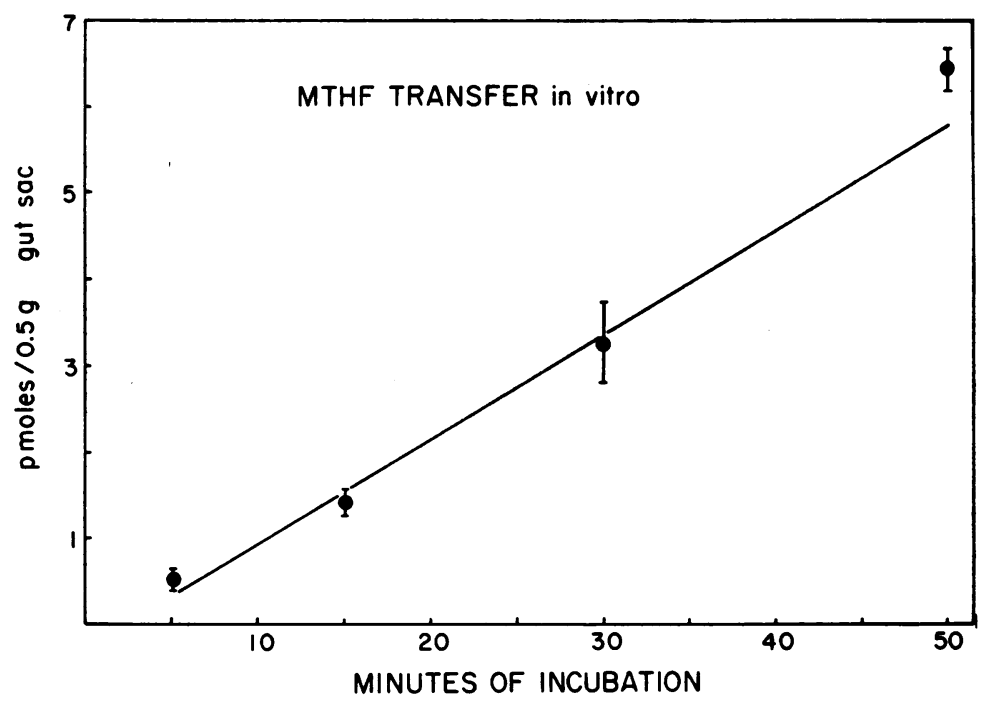

Figure 2 5-MTHF transfer from mucosa to serosa across an everted jejunal sac as a function of time. Three sacs from different animals were incubated at each time. See text for details.

transport or movement against the concentration gradient has $(1,4-7)$ and has not $(2,3,8,10)$ been obtained. Our evaluation of two of these studies $(1,7)$ suggest that the original conclusions indicating the presence of saturation kinetics may need modification. Cohen (5) originally suggested that the apparent accumulation of FA against a concentration gradient could be accounted for by the conversion of FA to reduced folate by hamster jejunum. Additional evidence of the reduction and methylation by FA by the intestinal mucosa has been observed in rat $(24)$, and in man $(9,25)$, although reduction and methylation of FA by the human intestine has been disputed (26). Whether these differences are explained by species and concentration differences is not known, but the question requires further study. FA, however, is not the major dietary form of folate. Analysis of liver, pea seedlings, yeast, and milk, indicates that significant amounts of reduced folate, primarily 5-MTHF, are found $(11,27-29)$. Further, analytical methods would tend to underestimate the reduced folate forms, and some of these reduced forms may exist as polyglutamates (12).

Synthesis of highly purified, radiolabeled 5-MTHF in our laboratory has facilitated the study of the absorption of this physiologic folate compound, 5-MTHF (13). Intestinal absorption of 5-MTHF was studied in the rat by several different in vitro methods: everted intestinal sacs, mucosal scrapings, and unidirectional transmural fluxes. These investigations indicate that 5-MTHF is transferred unchanged across the rat small intestine and suggest that the mechanism of 5-MTHF absorption is a nonenergy dependent process. These conclusions are supported by $(a)$ the failure to demonstrate movement of 5-MTHF against a concentration gradient in the everted sac experiments, lack of accumulation of 5-MTHF within the intestinal mucosa in mucosal scraping, and no net flux of 5-MTHF in the unidirectional transmural flux studies; $(b)$ the absence of saturation kinetics in that an increase in 5-MTHF mucosal to serosal transfer was linearly related to increased mucosal concentration of $5-\mathrm{MTHF}$; $(c)$ the inability to inhibit the rate of 5-MTHF transfer with either nitrogen replacement or the addition of a metabolic inhibitor, dinitrophenol; and $(d)$ the failure to inhibit 5-MTHF transfer significantly with folate analogues, FA and MTX. A preferential site of 5-MTHF absorption in the small intestine was not observed. Absorption was quantitatively similar in the duodenum, jejunum, and ileum.

These studies in the rat were performed in vitro and must be confirmed in man before our conclusions can be extended. Although it is conceivable that at lower 5-MTHF concentrations a carrier-mediated system might be identified, it is doubtful that folate concentrations below those used in these studies would have physiologic significance.

The stimulation of 5-MTHF transfer by 5-fTHF is unexplained. However, Goldman (30) recently reported that in L 1210 cells, the presence of 5-fTHF intracellularly will stimulate both $5-\mathrm{MTHF}$ and MTX influx. $\mathrm{He}$ has suggested that this observation could be explained by counter flow or counter transport. It would be intriguing to speculate that a similar mechanism exists in the gut. However, our studies do not indicate the presence of a carrier-mediated system in the small intestine. 


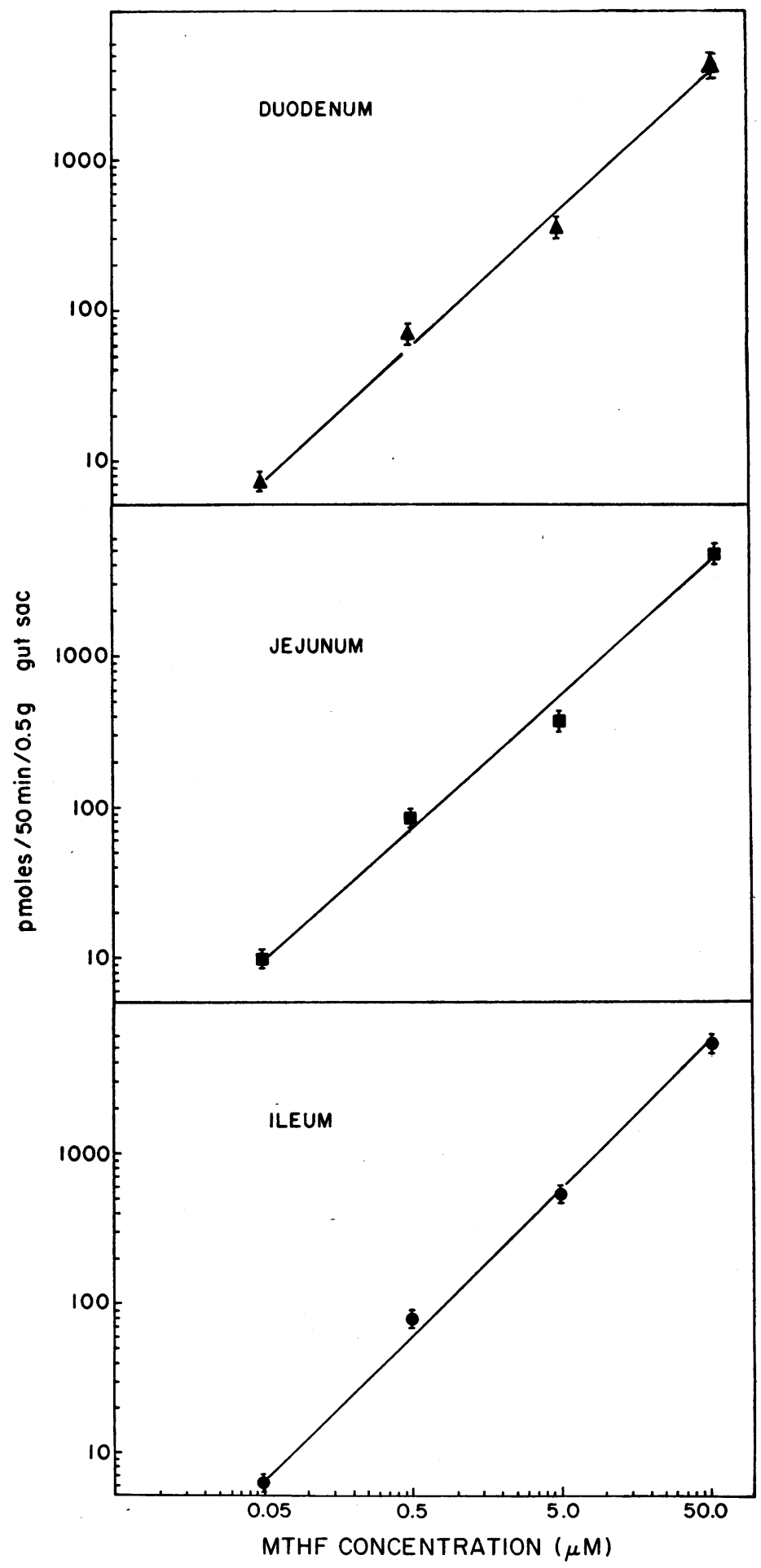

FIGURE 3 5-MTHF transfer across duodenal, jejunal, and ileal everted sacs as a function of increasing 5-MTHF concentration in the mucosal media. An average of nine sacs from each segment was studied at each concentration. 


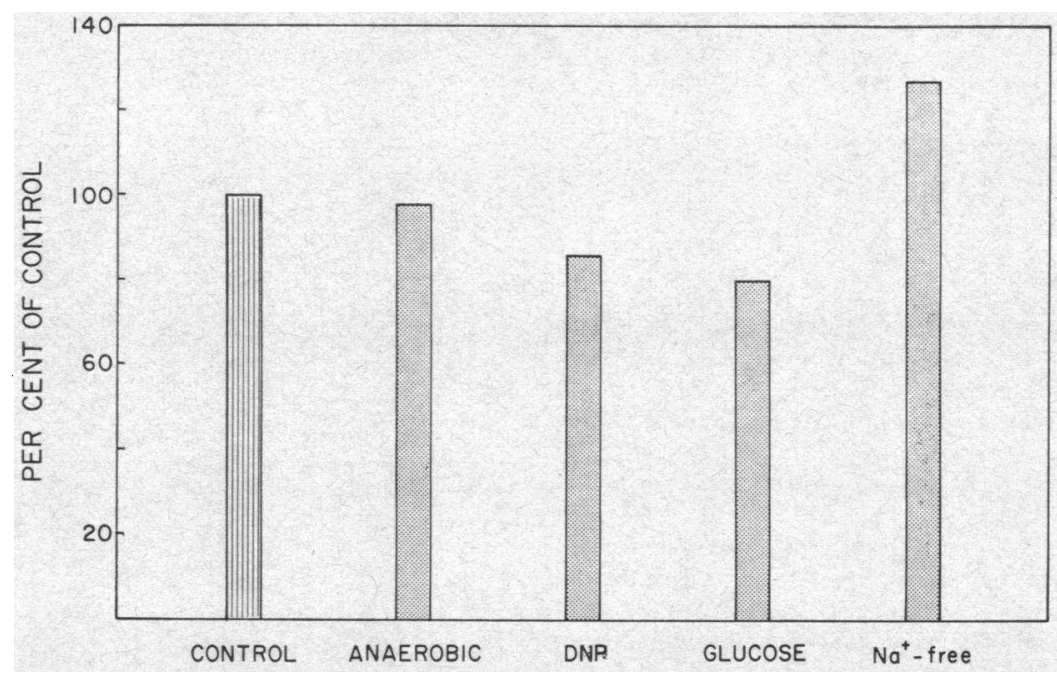

FiguRE 4 5-MTHF transfer was determined with several variations of the incubation conditions as described in the text. The differences observed between experiments and paired control studies were not significant.

Evidence to suggest carrier-mediated transfer of folate has been reported in L $5178 \mathrm{Y}$ leukemia cells (31), L 1210 leukemia cells $(32,33)$, lymphocytes (34), and across the blood brain barrier in dogs (35). FA transfer in platelets (36) and Lactobacillus casei (37) does not appear to be carrier mediated and, as previously noted, conflicting evidence exists whether FA is actively transported in the small intestine.

Our studies do not indicate the existence of a carriermediated system but rather suggest that 5-MTHF mucosal transfer occurs by a nonenergy dependent nonsaturable system.

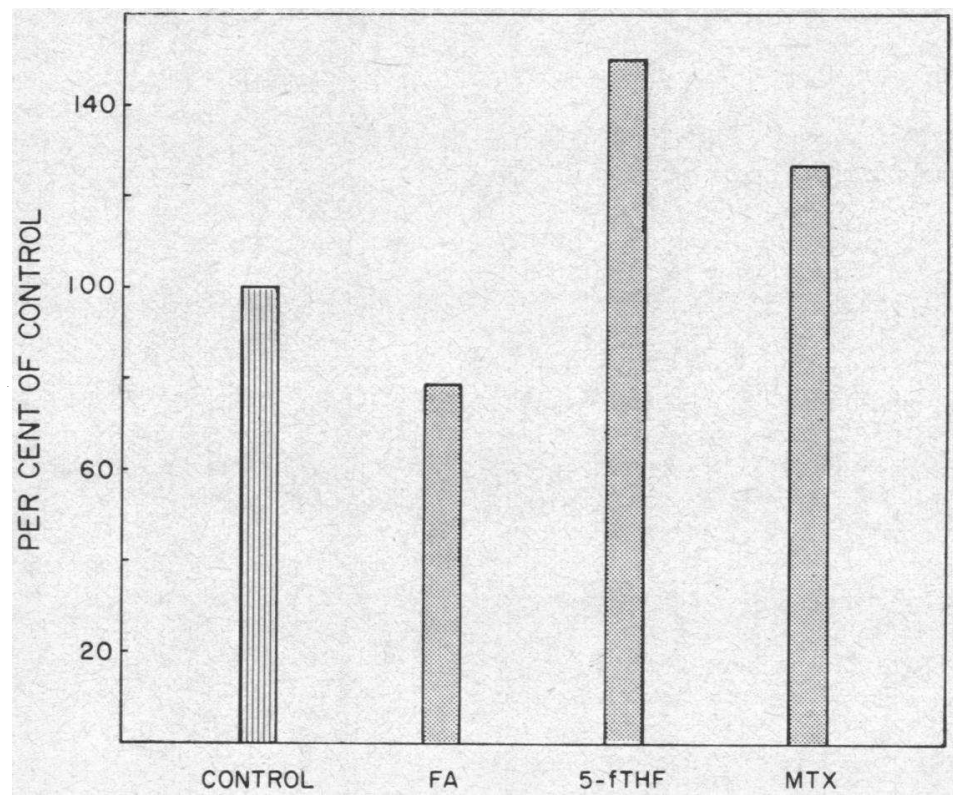

FIGURE 5 MTHF transfer was determined in the presence of various folate analogues as described in the text. In the presence of FA and MTX, the differences in 5-MTHF transfer were not significant from those of paired control studies. 5-MTHF transfer was significantly increased in the presence of 5-fTHF. 


\section{ACKNOWLEDGMENTS}

The authors acknowledge the technical assistance of Mrs. Judy Uhoch.

This investigation was supported in part by Grants CA 08341, CA 08010, and FR-05358 from the U. S. Public Health Service.

\section{REFERENCES}

1. Burgen, A. S. V., and N. J. Goldberg. 1962. Absorption of folic acid from the small intestine of the rat. Brit. J. Pharmacol. Chemother. 19: 313.

2. Turner, J. B., and D. E. Hughes. 1962. The absorption of some B-group vitamins by surviving rat intestine preparations. Quart. J. Exp. Physiol. Cog. Med. Sci. 47: 107.

3. Spencer, R. P., and T. M. Bow. 1964. In vitro transport of radiolabeled vitamins by the small intestine. J. Nucl. Med. 5: 251 .

4. Herbert, V. 1967. Biochemical and hematologic lesions in folic acid deficiency. Amer. J. Clin. Nut. 20: 562.

5. Cohen, N. 1965. Differential microbiological assay in study of folic acid absorption in vitro by everted intestinal sacs. Clin. Res. 13: 252. (Abstr.)

6. Hepner, G. W., C. C. Booth, J. Cowan, A. V. Hoffbrand, and D. L. Mollin. 1968. Absorption of crystalline folic acid in man. Lancet. $2: 302$.

7. Hepner, G. W. 1969. The absorption of pteroylglutamic (folic) acid in rats. Brit. J. Haematol. 16: 241.

8. Yoshino, T. 1968. The clinical and experimental studies on the metabolism of folic acid using titriated folic acid II. The experimental studies on the absorption site and mechanism of tritiated folic acid in rats. J. Vitaminol. $(K y$ 'oto $)$. 14: 35 .

9. Butterworth, C. E., Jr., C. M. Baugh, and C. Krumdieck. 1969. A study of folate absorption and metabolism in man utilizing carbon-14-labeled polyglutamates synthesized by the solid phase method. J. Clin. Invest. 48: 1131.

10. Smith, M. E., A. J. Matty, and J. A. Blair. 1970. The transport of pteroylglutamic acid across the small intestine of the rat. Biochim. Biophys. Acta. 219: 37.

11. Noronha, J. M., and M. Silverman. 1962. Distribution of folic acid derivatives in natural material. I. Chicken liver folates. J. Biol. Chem. 237: 3299.

12. Butterworth, C. E., Jr., R. Santini, Jr., and W. B. Frommeyer, Jr. 1963. The pteroylglutamate components of American diets as determined by chromatographic fractionation. J. Clin. Invest. 42: 1929.

13. Nixon, P. F., and J. B. Bertino. 1971. Enzymatic preparation of radiolabelled $(+)$ L-5 methyltetrahydrofolate and (+) L-5 formyltetrahydrofolate. Anal. Biochem. In press.

14. Blakley, R. L. 1960. Crystalline dihydropteroylglutamic acid. Nature (London). 188: 231.

15. Mathews, C. K., and F. M. Huennekens. 1960. Enzymic preparation of the $\lambda$, L-diastereoisomer of tetrahydrofolic acid. J. Biol. Chem. $235: 3304$.

16. Nixon, P. F., and J. R. Bertino. 1971. Separation and identification of folate coenzymes on DEAE-Sephadex. Methods Enzymol. 18: 661.

17. Wilson, T. H., and G. Wiseman. 1954. The use of sacs of everted small intestine for the study of the transference of substanes from the mucosal to the serosal surface. J. Physiol. (London). 123: 116.
18. Schultz, S. G., R. E. Fuisz, and P. F. Curran. 1966. Amino acid and sugar transport in rabbit ileum. $J$. Gen. Physiol. 49: 849.

19. Schultz, S. G., and R. Zalusky. 1964. Ion transport in isolated rabbit ileum. I Short-circuit current and $\mathrm{Na}$ fluxes. J. Gen. Physiol. $47: 567$.

20. Binder, H. J., L. A. Katz, R. P. Spencer, and H. M. Spiro. 1966. The effects of inhibitors of renal transport on the small intestine. J. Clin. Invest. 45: 1854.

21. Field, M., S. G. Schultz, and P. F. Curran. 1967. Alanine transport across isolated rabbit ileum. Biochim. Biophys. Acta. 135: 236.

22. Snedecor, G. W. 1956. Statistical Methods Applied to Experiments in Agriculture and Biology. Iowa State University Press, Ames, Iowa. 5th edition.

23. Ussing, H. H. 1949. The distinction by means of tracers between active transport and diffusion. The transfer of iodine across the isolated frog skin. Acta Physiol. Scand. 19: 43.

24. Strum, W. B., P. F. Nixon, H. J. Binder, and J. R. Bertino. 1970. Intestinal absorption of 5-methyltetrahydrofolate (MTHF). Clin. Res. 18: 389. (Abstr.)

25. Perry, J., and I. Chanarin. 1970. Intestinal absorption of reduced folate compounds in man. Brit. J. Haematol. $18: 329$.

26. Whitehead, V. M., and B. A. Cooper. 1967. Absorption of unaltered folic acid from the gastro-intestinal tract in man. Brit. J. Haematol. 13: 679.

27. Bird, O. D., V. M. McGlohon, and J. W. Vaitkus. 1965. Naturally occurring folates in the blood and liver of the rat. Anal. Biochem. 12: 18.

28. Roos, A. J., A. M. Spronk, and E. A. Cossins. 1968. 5-Methyltetrahydrofolic acid and other folate derivatives in germinating pea seedlings. Can. J. Biochem. 46: 1533.

29. Ramasastri, B. V. 1965. Folate activity in human milk. Brit. J. Nutr. 19: 581 .

30. Goldman, I. D. 1971. A model system for the study of heteroexchange diffusion methotrexate-folate interactions in L1210 leukemia cells and Ehrlich ascites tumor cells. Biochim. Biophys. Acta. 233: 624.

31. Fischer, G. A. 1962. Defective transport of amethopterin (methotrexate) as a mechanism of resistance to the antimetabolite in L5178Y leukemic cells. Biochem. Pharmacol. $11: 1233$.

32. Nahas, A., P. F. Nixon, and J. R. Bertino. 1969. Transport of 5-methyltetrahydrofolate by L1210 mouse leukemia cells. Fed. Proc. 28: 389. (Abstr.)

33. Goldman, I. D., N. S. Lichtenstein, and V. T. Oliverio. 1968. Carrier-mediated transport of the folic acid analogue, methotrexate, in the L1210 leukemia cell. J. Biol. Chem. 243: 5007.

34. Das, K. C., and A. V. Hoffbrand. 1970. Studies of folate uptake by phytohaemagglutinin-stimulated lymphocytes. Brit. J. Haematol. 19: 203.

35. Levitt, M., P. F., Nixon, J. H. Pincus, and J. R. Bertino. 1971. Transport characteristics of folates in cerebrospinal fluid; a study utilizing doubly labeled 5methyltetrahydrofolate and 5-formyltetrahydrofolate. $J$. Clin. Invest. 50: 1301.

36. Gaut, Z. N., H. M. Solomon, and C. M. Baugh. 1970. Accumulation of $\left[3^{\prime}, 5^{\prime}-{ }^{3} \mathrm{H}_{2}\right]$ folic acid by human blood platelets. Effect of dihydrofolic acid reductase inhibitors. Biochim. Biophys. Acta. 215: 194.

37. Cooper, B. A. 1970. Studies of $\left({ }^{8} \mathrm{H}\right)$ folic acid uptake by Lactobacillus casei. Biochim. Biophys. Acta. 208: 99. 